\title{
A Gap Analysis of Noncognitive Constructs in Evaluation Instruments Designed for Computing Education
}

\author{
Monica M. McGill \\ Knox College \\ Galesburg, IL, USA \\ mmmcgill@knox.edu \\ Tom McKlin \\ The Findings Group \\ Decatur, GA, USA \\ tom@thefindingsgroup.org
}

\author{
Adrienne Decker \\ University at Buffalo \\ Buffalo, NY, USA \\ adrienne@buffalo.edu \\ Kathy Haynie \\ Haynie Research and Evaluation \\ Skillman, NJ, USA \\ kchaynie@alumni.stanford.edu
}

\begin{abstract}
A growing body of evidence indicates that there is a deep effect of noncognitive factors on academic achievement and learning. In this study, we analyzed a set of 31 evaluation instruments designed to measure noncognitive constructs (e.g., self-efficacy, confidence, motivation) within computing education. Using the Lee and Shute framework, we assigned each of the 115 unique constructs found in the instruments into one of the four components (Student Engagement, Learning Strategies, School Climate, Social-familial Influences) and their subcomponents to determine which constructs are most frequently measured. We found that the majority of constructs were designed to measure Student Engagement (Affect and Cognition) and School Climate (Teacher Variables). Constructs measuring Learning Strategies and Social-Familial Influences (e.g., homework strategies, peer influences) occur the least. This study may enable further discussions of what noncognitive factors are/are not currently being measured within the computing education community.
\end{abstract}

\section{CCS CONCEPTS}

- Social and professional topics $\rightarrow$ Computing education; Computing education programs; Computer science education.

\section{KEYWORDS}

Evaluation, assessment, constructs, noncognitive, education

\section{ACM Reference Format:}

Monica M. McGill, Adrienne Decker, Tom McKlin, and Kathy Haynie. 2019. A Gap Analysis of Noncognitive Constructs in Evaluation Instruments Designed for Computing Education. In Proceedings of the 50th ACM Technical Symposium on Computer Science Education (SIGCSE '19), February 27-March 2, 2019, Minneapolis, MN, USA. ACM, New York, NY, USA, Article 4, 7 pages. https://doi.org/10.1145/3287324.3287362

This work is licensed under a Creative Commons Attribution-NonCommercial-ShareAlike International 4.0 License.

SIGCSE '19, February 27-March 2, 2019, Minneapolis, MN, USA

(C) 2019 Copyright held by the owner/author(s).

ACM ISBN 978-1-4503-5890-3/19/02.

https://doi.org/10.1145/3287324.3287362

\section{INTRODUCTION}

A growing body of empirical evidence indicates that noncognitive factors significantly affect academic achievement and learning [3, 11, 18, 28]. Most importantly, noncognitive factors are strongly related to the limited participation of women and minority students in computer science [11]. Studies have shown that non-majority students often feel that they do not belong in CS, and perceive that CS is the domain of white males, and does not serve socially progressive agendas (e.g. programming for good) nor allow for creative expression $[11,21,30]$.

Farkus defines noncognitive constructs as "...any skills, behaviors, habits, tendencies, traits, and disposition that are typically not measured by tests" (see Figure 1) [10]. Examples of noncognitive constructs include self-efficacy, study skills of students, support of family and friends, and sense of belonging [10,11,22]. Although the terms cognitive and noncognitive are currently understood as interdependent in the fields of psychology, education, and economics, we concur with Farrington, et al., that maintaining a distinction between the two can shed further light on research-based factors within the field of educational psychology [11].

Figure 1: $\odot$ The Consortium on Chicago School Research and Jeff Hall Design [11]. Used with permission.

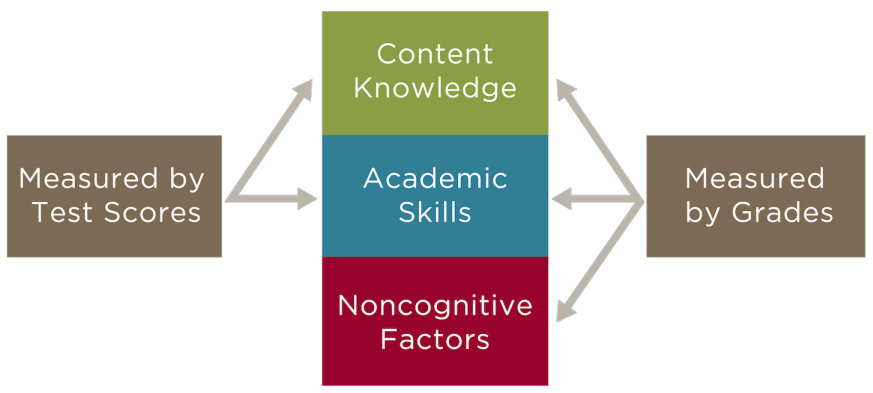

This study provides a taxonomy of existing research-based evaluation instruments that measure noncognitive constructs in computing education. Our overarching research question is: Which noncognitive constructs are and are not currently being measured in instruments specifically designed for evaluating the impact of computing education?

This meta-analytic research is relevant for CS education researchers who want to strengthen and improve the quality of their 
research and CS education evaluators intending to utilize rigorous evaluation instruments for measuring noncognitive factors. It is also foundational for practitioners and policy-makers who want to expand the repertoire of existing instruments by creating scales for measuring constructs that are not yet measured [11, 28].

\section{BACKGROUND}

Several frameworks model the affect noncognitive constructs have on student achievement. Farrington et al. identify five categories of noncognitive factors as well as their interdependencies [11]:

- Academic behaviors (attending class, doing homework, etc.)

- Academic perseverance (e.g. grit, self-control, self-discipline)

- Academic mindsets (e.g. positive or negative mindsets related to belonging, abilities, competencies)

- Learning strategies (e.g. study skills, metacognitive strategies, self-regulated learning), and

- Social skills (e.g. interpersonal skills, empathy, cooperation)

Farrington et al. make a strong case that not only do these factors influence academic achievement, they also influence later life outcomes, including success in the labor market. They further note that recent research indicates that emphasizing noncognitive learner factors "would yield high payoffs in improved educational outcomes as well as reduced racial/ethnic and gender disparities in school performance and educational attainment" [11, Chapter 1].

This model focuses on noncognitive factors centered on the learner. In contrast, Marzano's model was developed based on effect size through meta-studies. Three groupings (student-level, teacher-level, and school-level) were created based on the most significant effect sizes [22]. This model includes teacher-level factors (e.g. individual teacher effects, instructional strategies, curriculum design) and school-level factors (e.g. guaranteed/viable curriculum, challenging goals, effective feedback, parental/ community involvement, safe/orderly environment, and collegiality/ professionalism). This model acknowledges the breadth of variables outside students' control that have been shown to impact achievement.

Lee \& Shute propose a Personal and Social Contextual Factors framework. Similar to Marzano, their well-defined framework was formed through an extensive analysis of effect sizes reported by several longitudinal meta-studies of the impact of noncognitive factors on learning and student achievement [18]. Like other frameworks, Lee \& Shute recognize the reciprocity between the components and subcomponents-they interact and influence each other.
The four major components of this model (Student Engagement, Learning Strategies, School Climate, Social-familial Influences) each have several subcomponents (see Figure 2). Student Engagement has three: behavior defined as "students' external behaviors indicative of their interest and investment in learning activities"; cognitivemotivational engagement defined as "students' decisions, beliefs, and willingness to expand their efforts to learn and overcome challenging situations"; and emotional engagement defined as "student's affective reactions and feelings toward learning in general, as well as toward school, teachers, and classmates" [18](pp. 4-5).

Learning Strategies also has three subcomponents: cognitive, metacognitive, and behavioral learning strategies. Cognitive strategies refers to "skills that support learners as they develop internal procedures that enable them to perform complex tasks". Metacognitive strategies refers to "the abilities of learners to acknowledge, monitor, and evaluate their own cognitive processes as well as their strengths and weaknesses as learners." Behavioral learning strategies refers to "habitual activities that students employ during learning to manage and control their own behavior...behavior of others...and resources" [18](p 7). Learning strategies is further divided into individual constructs due to their well-studied impact on student achievement: time management, test-taking strategies, help-seeking, homework management, and test-taking skills.

School Climate is defined as "organizational characteristics that are persistent in and unique to a particular school" with four subcomponents: academic emphasis (students', parents', teachers', and administrators' "perception[s] of the importance of academic achievement"), teacher variables ("what teachers do in the classroom and how they interact with students and other teachers"), principal leadership ("principal's ability to influence the actions of school community members including teachers, parents, students, and district or state personnel"), and other school climate variables (e.g. sufficient resources, appropriate space, extracurricular activities).

Social-familial Influences are influences outside of school that impact student achievement. Lee \& Shute note two subcomponents: parental involvement (general attitudinal and behavioral components of parental involvement on student achievement) and peer influences (peer support, attitudes, and achievement levels).

For the remainder of this article, we adapt Lee \& Shute's terms, referring to Student-Personal and Social-Contextual as factors, Student Engagement, Learning Strategies, School Climate, and SocialFamilial Influences as components, and any category underneath

Figure 2: Lee \& Shute model [18]. ${ }^{*}$ indicates that the subcomponent has additional constructs discussed in section 4.

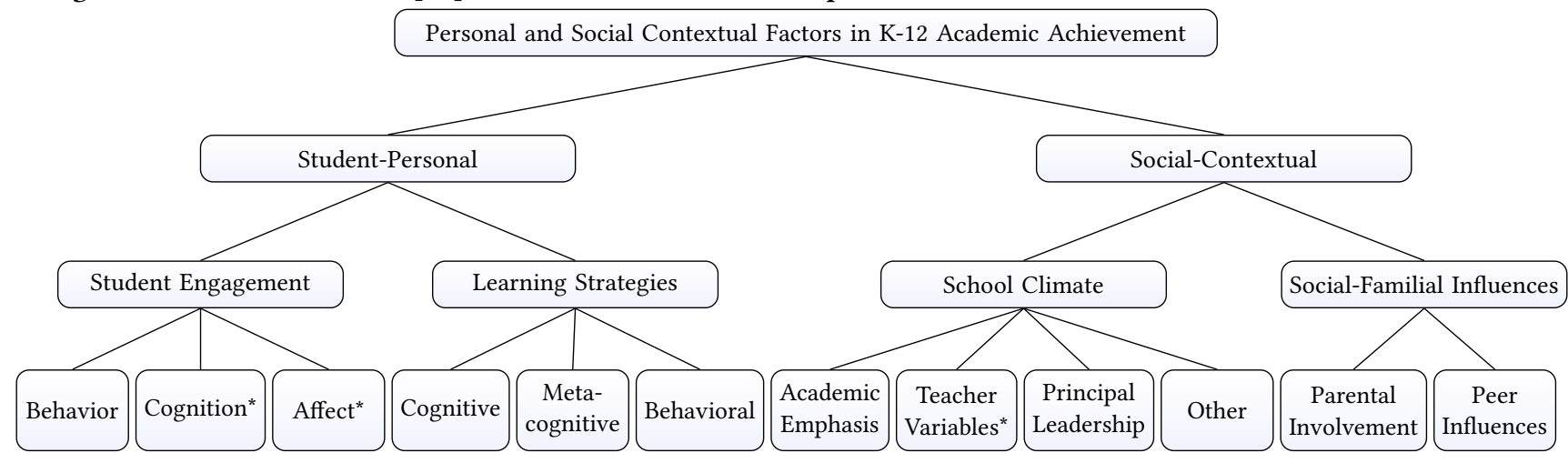


these as subcomponents. Subcomponents are further broken into constructs in the results section.

\section{METHODOLOGY}

To identify the noncognitive constructs being measured by evaluation instruments designed for computing education, we first needed to identify a set of instruments to study. To do so, we:

- Examined 297 articles published from 2012 to 2016 in the https://csedresearch.org database (2012-2016), noting instruments used in studies [23],

- Searched several online databases for instruments, including American Evaluation Association [2], STELAR [9] The Pear Institute [27], Institute for the Integration of Technology into Teaching and Learning [13], MSPNet [12], Engineering is Elementary [25], and

- Used search engines to perform searches based on relevant keywords (e.g., computer science, inventory, survey, instrument, evaluation, interest, self-efficacy, etc.).

After creating the initial set, we solicited the CS education community for additional instruments using the SIGCSE-Members listserv and computing education social media sites. With a total of 47 evaluation instruments, we reviewed each instrument to determine if it measured cognitive or noncognitive factors or assessed programs, or a combination of these. Due to limited space, we include the final list of instruments analyzed in this study in the Appendix of the companion paper published in these same proceedings [7].

Since noncognitive constructs may explain changes in student success in computing education, we carefully reviewed each of the 31 instruments to identify the noncognitive constructs that they set out to measure. Construct identification was completed by two independent coders. To help ensure inter-rater reliability, each coder was given an initial set of five instruments from which to identify constructs. This was done by examining the instruments and locating articles by the authors that defined the constructs measured. They then compared the constructs that they identified, resolving any discrepancies through discussion. The remaining instruments were divided among each coder, who then independently verified the constructs measured within each.

Many of the constructs found are documented in general education research literature and some in computer science education literature (e.g., sense of belonging, identity, anxiety, grit, interest, cognitive load, self efficacy) [1, 4, 5, 11, 14, 18, 19, 22, 24, 29]. As our use of these constructs in computer science interventions grows, so does our need to organize them for further analysis and discussion. After reviewing several models, we chose to adopt Lee \& Shute's model for categorizing the constructs due to its holistic structure in terms of the learning ecosystem. By using this model, we could identify where our current use of psychosocial constructs within these instruments flourish as well as those that fall short, all within the broader context of educational research.

Categorization of the constructs was carried out by the same two researchers who identified the constructs. Full intercoder reliability was achieved since the coders worked together to place the constructs in the corresponding components/subcomponents. To determine proper placement, the formal definitions of the components and subcomponents as defined by Lee $\&$ Shute were used. The coders worked together to discuss where each construct (from each of the evaluation instruments) belonged within the framework. For example, Fixed Mindset was measured in one of the instruments. We then took the construct as it was defined in the instrument and evaluated the components and subcomponents. Based on these definitions, we determined that Fixed Mindset was a Student Engagement factor related to Cognitive-Motivational Engagement. From there, we then decided it fit best within the Attribution for Success/Failure category. This process continued until each construct from each of the instruments was assigned to an appropriate subcomponent.

\section{RESULTS}

This section provides the resulting grouping of constructs within the components and subcomponents of the Lee \& Shute model. This section is divided into four subsections aligned with the components of the Lee \& Shute model: Student Engagement, Learning Strategies, School Climate, and Social-Familial Influences. We conclude with a summary of how well each component is covered.

In each of the tables provided, we list each subcomponent and, when available, individual constructs identified by Lee \& Shute within each subcomponent. We then show the constructs from the evaluation instruments within each where it made the most sense. For a few of these constructs, placement was less than a perfect match. We note these particular constructs with two asterisks $\left({ }^{* *}\right)$.

\subsection{Student-Personal: Student Engagement}

We found many constructs for Student Engagement across the 31 instruments (Table 1). Lee \& Shute identify seven constructs in the Cognition subcomponent (e.g., Attribution for Success/Failure, Confidence, Goal Orientation) and four constructs within Affect (e.g., Feelings toward school/learning, Interest/Curiosity) as having a profound impact on student achievement. We placed constructs from the instruments in the components where they best fit.

The Cognition and Affect subcomponents are captured more robustly in this set of instruments than Behavior, which only had six constructs. Some are measured more frequently than others. Self-concept, self-discipline, and feeling proud of academic accomplishments were measured less frequently than sense of belonging, self-efficacy, and intent/curiosity.

\subsection{Student-Personal: Learning Strategies}

Table 2 provides the set of subcomponents for Learning Strategies. We found that one instrument covered the cognitive strategies category of this model (instances and sources of repairs). Metacognition and behavioral strategies are weakly covered. We particularly note that none of the evaluation instruments evaluated behavioral strategies related to time management, test-taking strategies, or note-taking strategies, although all have been shown to significantly impact student achievement and learning.

\subsection{Social-Contextual: School Climate}

Table 3 provides the set of constructs for School Climate. Lee \& Shute define four constructs under Teacher Variables: Motivation, Affect, Cognition, and Meta-Cognition. We placed constructs from the evaluation instruments in each of these four as appropriate. 
Table 1: Student-Personal Factors: Student Engagement

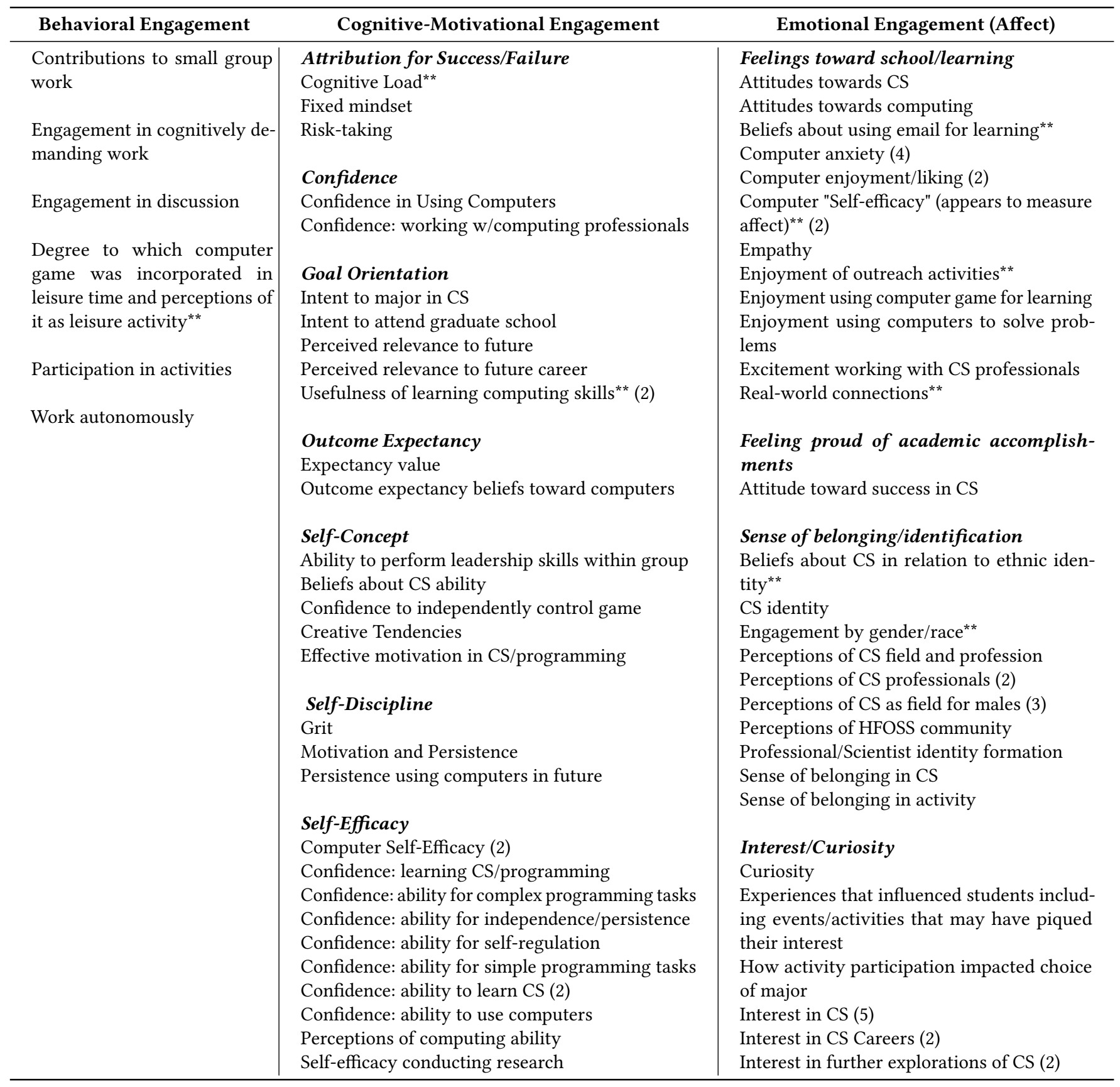

Table 2: Student-Personal Factors: Learning Strategies

\begin{tabular}{|c|c|c|c|}
\hline Cognition & Meta-Cognition & Behavior & \\
\hline $\begin{array}{l}\text { Instances and sources } \\
\text { of repairs (Statement } \\
\text { or question correction } \\
\text { by teacher or student) }\end{array}$ & $\begin{array}{l}\text { Is focus of learning on the "how" or the "why" } \\
\text { Knowledge Transfer } \\
\text { Perception of impact of a computer game on learning } \\
\text { Problem solving strategies } \\
\text { Self-assessed level of technological adoption }\end{array}$ & $\begin{array}{l}\text { Help-seeking } \\
\text { Homework Management } \\
\text { Time Management, Test-taking } \\
\text { and Note-taking Strategies }\end{array}$ & $\begin{array}{l}\text { Help-seeking and cop- } \\
\text { ing behaviors } \\
\text { Study Habits } \\
\text { none }\end{array}$ \\
\hline
\end{tabular}


Table 3: Social-Contextual Factors: School Climate

\begin{tabular}{|c|c|c|c|}
\hline $\begin{array}{l}\text { Academic } \\
\text { Emphasis }\end{array}$ & $\begin{array}{r}\text { Teac } \\
\text { Varia }\end{array}$ & & $\begin{array}{c}\text { Other School } \\
\text { Variables }\end{array}$ \\
\hline $\begin{array}{l}\text { Like/dislike } \\
\text { of school }\end{array}$ & $\begin{array}{l}\text { Motivation } \\
\text { Accommodating of computers } \\
\text { Attitudes about computing } \\
\text { Beliefs about CS teaching ability } \\
\text { Beliefs about impact of technology on society } \\
\text { Beliefs about requiring CS } \\
\text { Beliefs about productivity of technology } \\
\text { Beliefs about teaching ability (general) } \\
\text { Concern over impact of technology } \\
\text { Feelings about technology in classroom } \\
\text { Perceptions of computers } \\
\text { Perception of value of learning CS skills } \\
\text { Significance of learning about technology } \\
\text { Resourcefulness and coping } \\
\text { Utility of technology } \\
\text { Affect } \\
\text { Attitude toward teaching CS curriculum } \\
\text { Anxiety toward technology } \\
\text { Avoidance/Acceptance of technology } \\
\text { Comfort with technology } \\
\text { Enthusiasm/Enjoyment of technology } \\
\text { Interest in Technology }\end{array}$ & $\begin{array}{l}\text { Cognition } \\
\text { Absorption of technology into their } \\
\text { lives } \\
\text { Competency with technology use in } \\
\text { IT education } \\
\text { Email for classroom learning } \\
\text { Interaction with technology (e.g., } \\
\text { email) } \\
\text { Perception of cognitive demand in CS } \\
\text { Meta-Cognition } \\
\text { Confidence in ability to write a pro- } \\
\text { gram } \\
\text { Innovativeness } \\
\text { Self-efficacy in teaching program- } \\
\text { ming and CT }\end{array}$ & $\begin{array}{l}\text { Community support for CS } \\
\text { Community values/perceptions of } \\
\text { CS } \\
\text { How students receive help } \\
\text { Instructional Style } \\
\text { Interactions between students and } \\
\text { teacher } \\
\text { Nature of discourse in the class- } \\
\text { room } \\
\text { Resources available to students } \\
\\
\text { Note: We found no constructs in any } \\
\text { of the instruments that measured } \\
\text { Principal Leadership subcompo- } \\
\text { nent with respect to computing. }\end{array}$ \\
\hline
\end{tabular}

Table 4: Social-Contextual Factors: Social-Familial Influences

\begin{tabular}{l|l}
\hline \multicolumn{1}{c}{ Parental Involvement } & \multicolumn{1}{c}{ Peer Influences } \\
\hline Importance of learning computing & Friends/family in CS \\
Perceptions of careers in computing & Friends/family interest in CS \\
Perspective on computing & \\
Support for pursuit of computing careers & \\
\hline
\end{tabular}

While there is moderate coverage of the teacher variables across the 31 instruments, many of these are related to technology in the classroom and not particularly focused on computer science education. We also found that one subcomponent, Principal Leadership, receives no coverage and only found one construct across the instruments that covers Academic Emphasis.

\subsection{Social-Contextual: Social-Familial Influences}

Social-Familial components are not well covered by the current set of constructs within the instruments we analyzed (see Table 4). Parental involvement is covered by only four constructs. We placed two constructs within peer influences, although we note that they may not be a perfect fit within the Lee \& Shute model.

\subsection{Summary}

We found a total of 132 constructs being measured across the 31 instruments, with 115 of those being unique scales (or subscales) or uniquely contextualized into a program, course, or learning (see
Table 5). At the component level, over half (56.5\%) of the unique constructs measured Student Engagement and almost a third (31.3\%) measured School Climate. The least measured were Learning Strategies (7.0\%) and Social-Familial Influences (5.2\%).

The vast majority $(75.6 \%)$ of unique constructs measured were in just three subcomponents: Student Engagement: Affect (25.2\% of the unique constructs), Student Engagement: Cognition (26.1\%), and School Climate: Teacher Variables (24.3\%). Digging deeper, the 29 unique constructs measured in the Affect subcomponent were found across a subset of the 31 evaluation instruments, indicating that instrument authors have developed different instruments that measure a similar construct. For example, six instruments measure the construct Interest in CS: Computing Attitudes Survey [8], BASICS Study Student Implementation Questionnaire [26], Computer Science Attitude Survey [17], Robotics Activities Attitudes Scale [6], and Computer Science Attitude and Identity Survey [31].

The fewest constructs measured were School Climate: Principal Leadership (0 constructs found), Learning Strategies: Cognition (1), School Climate: Academic Emphasis (1), Learning Strategies: Behavior (2), and Social-Familial Influences: Peer Influences (2).

\section{DISCUSSION}

This works applies a well-established taxonomy of noncognitive factors in K-12 learning (Lee \& Shute) to the current body of instruments in the computing education literature, using a categorization that has not been previously accomplished in our field. There are several limitations. The study is based on a framework that was designed based on studies from K-12 education. Therefore, though 
Table 5: Number of constructs measured framed in the major components and subcomponents (Lee \& Shute)

\begin{tabular}{|c|c|c|c|}
\hline Component & Subcomponent & $\begin{array}{c}\text { Total } \\
\text { Constructs }\end{array}$ & $\begin{array}{c}\text { Unique } \\
\text { Constructs }\end{array}$ \\
\hline $\begin{array}{l}\text { Student } \\
\text { Engagement }\end{array}$ & $\begin{array}{l}\text { Behavior } \\
\text { Cognition } \\
\text { Affect } \\
\text { Subtotal } \\
\end{array}$ & $\begin{array}{r}6 \\
33 \\
43 \\
82\end{array}$ & $\begin{array}{r}6 \\
30 \\
29 \\
65\end{array}$ \\
\hline $\begin{array}{l}\text { Learning } \\
\text { Strategies }\end{array}$ & $\begin{array}{l}\text { Cognition } \\
\text { Meta-Cognition } \\
\text { Behavior } \\
\text { Subtotal }\end{array}$ & $\begin{array}{l}1 \\
5 \\
2 \\
8\end{array}$ & $\begin{array}{l}1 \\
5 \\
2 \\
8\end{array}$ \\
\hline $\begin{array}{l}\text { School } \\
\text { Climate }\end{array}$ & $\begin{array}{l}\text { Academic Emphasis } \\
\text { Teacher Variables } \\
\text { Principal Leadership } \\
\text { Other } \\
\text { Subtotal }\end{array}$ & $\begin{array}{r}1 \\
28 \\
0 \\
7 \\
36\end{array}$ & $\begin{array}{r}1 \\
28 \\
0 \\
7 \\
36\end{array}$ \\
\hline $\begin{array}{l}\text { Social-Familial } \\
\text { Influences }\end{array}$ & $\begin{array}{l}\text { Parental Involvement } \\
\text { Peer Influences } \\
\text { Subtotal }\end{array}$ & $\begin{array}{l}4 \\
2 \\
6\end{array}$ & $\begin{array}{l}4 \\
2 \\
6\end{array}$ \\
\hline TOTAL & & 132 & 115 \\
\hline
\end{tabular}

it may identify gaps in the instruments, it may miss others in higher education. Likewise, we worked with a limited set of evaluation instruments (31). Adding additional instruments to the set could improve the robustness of the list of noncognitive constructs that are measured.

We hope that this study initiates further discussion within the computing education research community, addressing questions such as:

(1) What is the nature of computer science learning, including knowledge, engagement, instructional and learning strategies, and social and contextual factors?

(2) What are our models of learning in computer science education, and how do these incorporate noncognitive factors?

(3) What assessments are needed to measure critical cognitive and noncognitive factors in computer science learning?

(4) How well does the current body of valid measures meet the community's needs to measure diverse and informative theories of change?

(5) What additional measures are needed to determine computer science implementations, outcomes and mitigating factors?

This current study has made a critical contribution to answer questions 1, 2, and 3, and provides an analysis of question 4 based on the Lee \& Shute framework and the current published computer science research literature. For question 5 , about additional measures needed (and if we take the Lee $\&$ Shute framework as a given representation of the noncognitive domain in computer science education), Table 5 indicates: (1) there is currently a large number of constructs within most dimensions of student engagement, (2) measures of very few constructs within the learning strategies factor currently exist, (3) a very large number of teacher variable constructs have existing measures, although principal leadership and school climate academic emphasis measures are lacking and (4) a small number of measures exist for social-family influences. These results suggest that a focus on the development and validation of learning strategy measures (for a variety of constructs and in a variety of contexts) is arguably a top priority.

The work to organize psychosocial constructs is promising in a number of ways. First, this work may help identify the participants who are measured more frequently. It may reveal that our instruments provide little data on women and underrepresented minorities and therefore little information on the constructs that predict success among these populations. Further, this organizational structure may also reveal that we primarily measure student participants, and that we have not adequately expanded our analyses to include classroom, school, and district-level variables that contribute to student success.

Second, an organizational structure may help to determine which constructs and components account for the greatest variance in student success. We recognize that one next step is to gather effect size information that connects constructs and components of the framework to measures of student success. This may open the door for synthesis research and meta-analyses that look across studies to find effects that may otherwise not appear [16].

Finally, many programs currently measure identity and belonging among computer science students. These related constructs are occasionally used synonymously or as a single set of items for measuring both. This framework may move us toward greater sensitivity among all our instruments to differentiate closely related constructs. Improved sensitivity may also help reveal the difference between learning computer science and other STEM disciplines [15]. For example, Lishinski et al. (2017) reveal that students have strong emotional reactions to programming exercises, a psychosocial construct that may be unique to CS and that may explain some of the variance in student success [20].

\section{CONCLUSION}

The analogy we often use to guide this work is that we are looking for the psychosocial equivalent of the periodic table to help researchers see the landscape of constructs that inform student success, to understand the unique weight of each construct for whom and under what conditions, and to reveal gaps in our toolbox of psychosocial measures. Researchers and evaluators face an ever growing number of possible tools to help measure interventions, and as these tools grow, we must collectively become adept at matching the most sensitive and accurate instruments to more discerning and unique theories of change. To do that, we need a framework that serves as a concept map and also a guide telling us whether the instrument will validly and reliably measure our theory. Our use of the Lee \& Shute framework is only a starting point in the classification of evaluation instruments designed for computing education research. We encourage researchers and evaluators to offer critiques that expand upon and improve the framework and the instruments as well.

\section{ACKNOWLEDGMENTS}

This material is based upon work supported by the U.S. National Science Foundation uder Grant Nos. 1625335, 1649671, 1745199, and 1757402 . 


\section{REFERENCES}

[1] Jeff Allen, Steven B Robbins, and Richard Sawyer. 2009. Can measuring psychosocial factors promote college success? Applied Measurement in Education 23, 1 (2009), 1-22.

[2] American Evaluation Association. 2018. American Evaluation Association. http: //www.eval.org/

[3] John D Bransford, Ann L Brown, and Rodney R Cocking. 2000. How People Learn: Brain, Mind, Experience, and School. National Academy Press. http: //books.nap.edu/catalog/9853.html

[4] Tor Busch. 1996. Gender, group composition, cooperation, and self-efficacy in computer studies. Journal of educational computing research 15, 2 (1996), 125-135.

[5] Jeanne Century, Mollie Rudnick, and Cassie Freeman. 2010. A framework for measuring fidelity of implementation: A foundation for shared language and accumulation of knowledge. American fournal of Evaluation 31, 2 (2010), 199-218.

[6] Jennifer Cross, Emily Hamner, Lauren Zito, Illah Nourbakhshh, and Debra Bernstein. 2016. Development of an assessment for measuring middle school student attitudes towards robotics activities. In Frontiers in Education Conference (FIE), 2016 IEEE. IEEE, 1-8.

[7] Adrienne Decker and Monica M. McGill. 2019. A Topical Review of Evaluation Instruments for Computing Education. In Proceedings of the 50th ACM Technical Symposium on Computer Science Education. ACM.

[8] Brian Dorn and Allison Elliott Tew. 2015. Empirical validation and application of the computing attitudes survey. Computer Science Education 25, 1 (2015), 1-36.

[9] Inc. Education Development Center. [n. d.]. STELAR. http://stelar.edc.org/ resources

[10] George Farkas. 2003. Cognitive skills and noncognitive traits and behaviors in stratification processes. Annual review of sociology 29, 1 (2003), 541-562.

[11] Camille A Farrington, Melissa Roderick, Elaine Allensworth, Jenny Nagaoka, Tasha Seneca Keyes, David W Johnson, and Nicole O Beechum. 2012. Teaching Adolescents to Become Learners: The Role of Noncognitive Factors in Shaping School Performance-A Critical Literature Review. ERIC.

[12] Center for School Reform at TERC. [n. d.]. MSPMaterials. http://hub.mspnet. org/index.cfm/msp_tools

[13] Institute for the Integration of Technology into Teaching and Learning. [n. d.] UNT Institute for the Integration of Technology. https:/iittl.unt.edu/content/ instruments

[14] Catherine Good, Aneeta Rattan, and Carol S Dweck. 2012. Why do women opt out? Sense of belonging and women's representation in mathematics. Fournal of personality and social psychology 102, 4 (2012), 700.

[15] Mark Guzdial. 2018. Learning Computer Science Is Different Than Learning Other STEM Disciplines. https://cacm.acm.org/blogs/blog-cacm/ 224105-learning-computer-science-is-different-than-learning-other-stem-disciplines/ fulltext. Accessed: 2010-07-21.

[16] John Hattie. 2008. Visible learning: A synthesis of over 800 meta-analyses relating to achievement. routledge.

[17] Andrew Hoegh and Barbara M Moskal. 2009. Examining science and engineering students' attitudes toward computer science. In Frontiers in Education Conference,
2009. FIE'09. 39th IEEE. IEEE, 1-6.

[18] Jihyun Lee and Valerie J Shute. 2010. Personal and social-contextual factors in K-12 academic performance: An integrative perspective on student learning. Educational Psychologist 45, 3 (2010), 185-202.

[19] Jihyun Lee and Lazar Stankov. 2018. Non-cognitive predictors of academic achievement: Evidence from TIMSS and PISA. Learning and Individual Differences 65 (2018), 50-64.

[20] Alex Lishinski, Aman Yadav, and Richard Enbody. 2017. Students' Emotional Reactions to Programming Projects in Introduction to Programming: Measurement Approach and Influence on Learning Outcomes. In Proceedings of the 2017 ACM Conference on International Computing Education Research. ACM, 30-38.

[21] J. Margolis and A. Fisher. 2003. Unlocking the Clubhouse: Women in Computing. MIT Press. https://books.google.com/books?id=StwGQw45YoEC

[22] Robert J Marzano. 2003. What works in schools: Translating research into action. ASCD.

[23] Monica M McGill, Adrienne Decker, and Zachary Abbott. 2018. Improving Research and Experience Reports of Pre-College Computing Activities: A Gap Analysis. In Proceedings of the 49th ACM Technical Symposium on Computer Science Education. ACM, 964-969.

[24] Briana B Morrison, Brian Dorn, and Mark Guzdial. 2014. Measuring cognitive load in introductory CS: adaptation of an instrument. In Proceedings of the tenth annual conference on International computing education research. ACM, 131-138.

[25] Boston Museum of Science. 2018. Research Instruments. https://www.eie.org engineering-elementary/research/research-instruments

[26] University of Chicago Outlier Resesarch \& Evaluation, UChicago STEM Education. 2017. BASICS Study Student Implementation Questionnaire. http://outlier. uchicago.edu/basics/resources/Measures-StudentImplementation/

[27] Afterschool PEAR (Program in Education and Resiliency). [n. d.]. PearInstitute. http://www.pearweb.org/atis/tools/jump

[28] Jeffrey A Rosen, Elizabeth J Glennie, Ben W Dalton, Jean M Lennon, and Robert N Bozick. 2010. Noncognitive Skills in the Classroom: New Perspectives on Educationa Research. ERIC.

[29] Lazar Stankov, Suzanne Morony, and Yim Ping Lee. 2014. Confidence: the best non-cognitive predictor of academic achievement? Educational Psychology 34, 1 (2014), 9-28

[30] Jennifer Wang, Sepehr Hejazi Moghadam, and Juliet Tiffany-Morales. 2017. Social Perceptions in Computer Science and Implications for Diverse Students. In Proceedings of the 2017 ACM Conference on International Computing Education Research (ICER '17). ACM, New York, NY, USA, 47-55. https://doi.org/10.1145/ 3105726.3106175

[31] Alicia N Washington, Shaefny Grays, and Sudhipta Dasmohapatra. 2016. The Computer Science Attitude and Identity Survey (CSAIS): A Novel Tool for Measuring the Impact of Ethnic Identity in Underrepresented Computer Science Students. In Proceedings of the ASEE's 123rd Annual Conference \& Exposition 2016. 